\title{
Post-learning molecular reactivation underlies taste memory consolidation
}

\author{
Kioko Guzmán-Ramos ${ }^{1}$ and Federico Bermúdez-Rattoni ${ }^{1,2}$ * \\ ${ }^{1}$ Department of Psychology, Texas A\&M University, College Station, TX, USA \\ ${ }^{2}$ División de Neurociencias, Instituto de Fisiología Celular, Universidad Nacional Autónoma de México, México City, México
}

Edited by:

Milagros Gallo, University of Granada, Spain

Reviewed by:

Milagros Gallo, University of Granada, Spain

Takashi Yamamoto, Osaka University Graduate School of Dentistry, Japan

\section{*Correspondence:}

Federico Bermúdez-Rattoni, División

de Neurociencias, Instituto de

Fisiología Celular, Universidad

Nacional Autónoma de México,

Ciudad Universitaria 04510, México

City, México.

e-mail: fbermude@ifc.unam.mx
It is considered that memory consolidation is a progressive process that requires posttrial stabilization of the information. In this regard, it has been speculated that waves of receptors activation, expression of immediate early genes, and replenishment of receptor subunit pools occur to induce functional or morphological changes to maintain the information for longer periods. In this paper, we will review data related to neuronal changes in the post-acquisition stage of taste aversion learning that could be involved in further stabilization of the memory trace. In order to achieve such stabilization, evidence suggests that the functional integrity of the insular cortex (IC) and the amygdala (AMY) is required. Particularly the increase of extracellular levels of glutamate and activation of $\mathrm{N}$-methyl-Daspartate (NMDA) receptors within the IC shows a main role in the consolidation process. Additionally the modulatory actions of the dopaminergic system in the IC appear to be involved in the mechanisms that lead to taste aversion memory consolidation through the activation of pathways related to enhancement of protein synthesis such as the Protein Kinase A pathway. In summary, we suggest that post-acquisition molecular and neuronal changes underlying memory consolidation are dependent on the interactions between the AMY and the IC.

Keywords: conditioned taste aversion, glutamate, dopamine, molecular reactivation, memory consolidation

\section{INTRODUCTION}

Memories of aversive events are more likely to persist over time. The strong and long-lasting representation of these memory traces may depend on the molecular mechanisms required for the consolidation process. A good example of a long-lasting memory trace representation is the conditioned taste aversion (CTA), a learning model where animals associate a novel taste (conditioned stimulus, CS) with gastric malaise (unconditioned stimulus, US), decreasing the CS intake in further presentations. This kind of learning can be acquired with only one-trial and the CS can be separated from the US by many hours, which allows a temporal resolution of the mechanisms involved in the gustatory stimulus acquisition and the further association with the gastric malaise (Naor and Dudai, 1996; Yamamoto et al., 1998; Welzl et al., 2001). Since this task involves the recognition and avoidance of toxic and potentially deadly food, the efficient consolidation and storage of this information makes CTA a good model to study the molecular mechanisms through which memories are established. Overall, these mechanisms would have to promote synaptic plasticity in the structures that are related to acquisition and storage of the information; among these, the insular cortex (IC) and the amygdala (AMY) are key structures involved in acquisition and consolidation of CTA (Bermudez-Rattoni, 2004).

\section{POST-ACQUISITION ACTIVATION AND TASTE MEMORY CONSOLIDATION}

Formation of long-term memories is based on molecular and structural changes that allow neuronal networks to stabilize and support long-term storage. It has been proposed that this consolidation process relies on memory trace reactivation seen as neuronal post-learning activity in absence of sensory stimulation. Trace reactivation theory establishes that the expression of patterns of activity in neural ensembles during an experience should be spontaneously re-activated during subsequent periods of behavioral inactivity: even during post-training wakefulness, indicating that information can be maintained and processed concurrently within relevant cortical sites (Hoffman and McNaughton, 2002). For instance, these authors made simultaneous neural recordings in the macaque neocortex, i.e., posterior parietal cortex, motor cortex, somatosensory cortex, and dorsal prefrontal cortex after a sequential reaching behavior, the simultaneous analysis revealed that cells in all four areas exhibited similar firing related to the task, and interestingly those cells tended to be coactive afterward. According to this hypothesis, memory consolidation relies on reactivation and reorganization of newly acquired information. After the initial encoding of sensorimotor experience, a series of cellular, molecular, and systems-level alterations develop over time, engaging reactivation patterns in neocortical structures during awareness and sleep periods, stabilizing the initial memory representation, converting it into a long-lasting memory trace (Smith, 2001; Robertson et al., 2004; Walker and Stickgold, 2004; Stickgold, 2005; Ellenbogen et al., 2006; Gais et al., 2007; Rasch and Born, 2007). Particularly in CTA learning, there is evidence suggesting that such post-learning activities may be part of the trace consolidation mechanisms. For instance, single unit recording in the basolateral nucleus of the amygdala (BLA) showed an increase 
of activity 30 min after CS-US pairing (Yamamoto and Fujimoto, 1991), and similar results were obtained from single unit recordings in the IC, where 20-30 min after CS-US pairing IC neurons had an increment of excitability (Yasoshima and Yamamoto, 1998). These reports suggest that the association between the CS and US could induce post-acquisition changes that create a long-lasting activation of these structures that may potentiate synaptic efficacy even after stimulation has ceased.

\section{CTA CONSOLIDATION: INSULAR CORTEX AND AMYGDALA}

Many studies have proven that two temporal lobe structures, the IC and the amygdala (AMY) are highly involved in taste memory formation. These studies have demonstrated either by lesions or by administration of several neurotransmitters antagonists before the CS presentation, that CTA is affected or impaired in one or both structures. Although, these effects could be evaluated performing a long-term memory (LTM) test, it is unclear if the affected stage was the acquisition or the consolidation of the memory trace. In order to evaluate this, a short-term memory (STM) test may clarify the role of some neurotransmitter systems in the different memory stages. For instance, the administration of scopolamine, a muscarinic antagonist, into the IC before CTA acquisition affected both STM and LTM indicating that the LTM effect is attributable to an impairment of the actual memory trace formation (Naor and Dudai, 1996; Ferreira et al., 2002). Conversely, blockade of the $N$-methyl-D-aspartate receptors (NMDAr) before CTA training impairs only LTM leaving STM intact, indicating that the activity of these receptors is required for memory consolidation (Ferreira et al., 2002; Bermudez-Rattoni, 2004). Another neurotransmitter system that has been involved in CTA memory consolidation is the dopaminergic system. Disruption of dopamine projections in the IC by the administration of a catecholaminergic toxin (6-hydroxydopamine) before CTA training, impairs acquisition of this task (Fernandez-Ruiz et al., 1993) and the blockade of the D1 type receptors before CTA training impairs LTM (Berman et al., 2000). Accordingly, we have seen by using in vivo microdialysis that the first presentation of taste stimuli, like saccharin or quinine, induces a significant increase of dopamine release but not glutamate within the IC, suggesting a differential role of these neurotransmitters in taste processing (Figures 1A,B). The dopaminergic increment is thought to be related to the novelty of the stimulus, since the presentation of water did not induce any significant changes in dopamine release and both saccharin $(0.1 \% \mathrm{v} / \mathrm{v}$, sweet $)$ and quinine $(0.005 \% \mathrm{v} / \mathrm{v}$, bitter) solutions, being different taste modalities, yet novel stimuli, induced a dopamine increase (Guzman-Ramos et al., 2010). Some evidences show similar results in other structures receiving dopaminergic aferences such as nucleus accumbens (Bassareo and Di Chiara, 1997; Feenstra et al., 2000) and prefrontal cortex (Bassareo and Di Chiara, 1997; Feenstra et al., 2000; Rossetti and Carboni, 2005; De Leonibus et al., 2006) during the exposure to novel stimuli. In this regard, it has been considered that dopaminergic responses are not only related to the rewarding quality of the stimuli, but also to their salience (Ljungberg et al., 1992; Ungless, 2004). For instance, a salient novel gustatory stimulus is important for the animals, since it can produce either favorable or aversive consequences. Hence, dopamine increase may be a suitable signal that triggers the mechanisms to store relevant information. In CTA training, we have addressed whether the dopaminergic signal related to the CS presentation was involved in the acquisition or the consolidation of the memory trace. To do so, we blocked the D1 receptors before the CS-US exposure and performed STM and LTM tests. Interestingly, pre-trial treatment only impaired LTM leaving STM intact; and when the D1 receptors were blocked just after the CS presentation, neither STM nor LTM were impaired (Figure 2), indicating that the dopaminergic action within the IC during the CS processing is involved specifically on CTA memory consolidation (Guzman-Ramos et al., 2010).

From this evidence we could say that both STM and LTM storage mechanisms are triggered during training. Muscarinic receptors are involved in STM, whereas D1 and NMDA receptors are activated to further consolidate the memory trace.

\section{PROTEIN SYNTHESIS INVOLVED IN POST-ACOUISITION ACTIVITY FOR TASTE MEMORY CONSOLIDATION}

Among the molecular differences between STM and LTM mechanisms is the dependence on protein synthesis (Davis and Squire, 1984; Martin et al., 2000; Dudai, 2004). The consolidation process

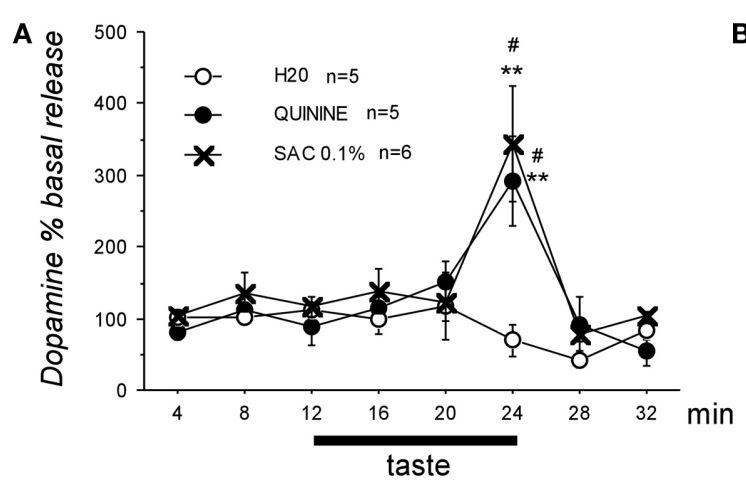

FIGURE 1 | (A) Dopamine and (B) glutamate release in the IC during the exposure to novel gustatory stimuli (saccharin $0.1 \%$, quinine $0.005 \%$ ) or water. Fractions of $4 \mu \mathrm{L}$, the first three samples are baseline release before taste stimulation. Data is shown as

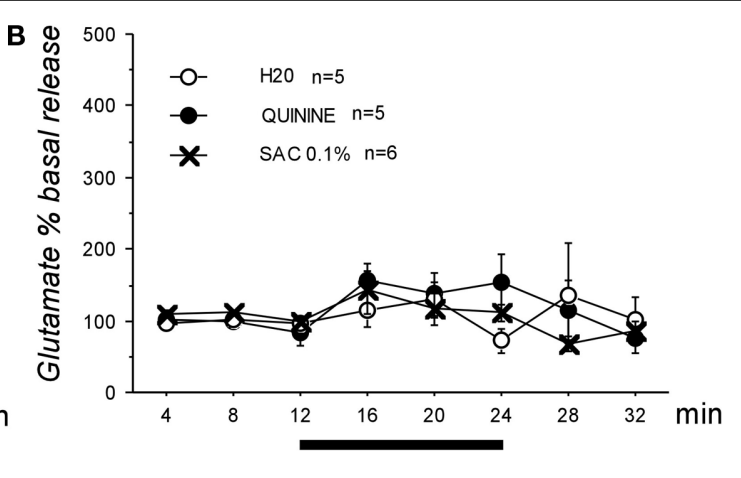

mean \pm SEM; ${ }^{*} p<0.05$ and ${ }^{* *} p<0.01$ vs. same fraction of control group and $\# p<0.05$ vs. baseline fractions. A significant increase of dopamine is shown in the $\mathrm{IC}$ of groups that were exposed to novel taste stimulation. 


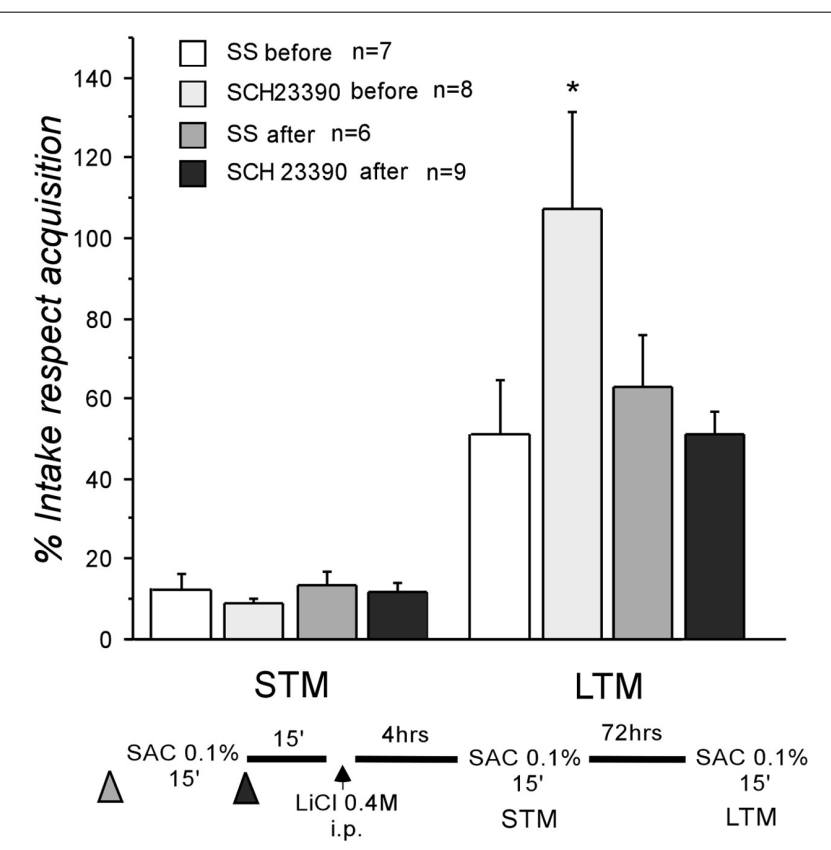

FIGURE 2 | Short- and long-term memory (STM and LTM) effects of the intra-cortical infusion of $\mathrm{SCH} 23390$, a D1 receptors antagonist, into the IC. "SCH23390 before" group and a control group that received saline solution injections (SS before) were injected $15 \mathrm{~min}$ prior CTA training (gray triangle) that consisted in the presentation of a saccharine solution (0.1\%) during $15 \mathrm{~min}$, followed by an i.p. $\mathbf{~} \mathbf{~ i C l}$ administration (0.4 M, 7.5 $\mathbf{~ L L / ~} \mathbf{k g})$. "SCH 23390 after" and SS after groups received the injections immediately after the saccharin exposure (black triangle). All the groups showed aversion in the STM test ( $4 \mathrm{~h}$ after conditioning), whereas in the LTM test (72 h) only the group that was injected with the D1 antagonist shows an impairment of consolidation. Saccharin consumption during the memory tests are expressed as percentage of consumption during acquisition stage \pm SEM. ${ }^{*} p<0.05$.

is thought to be a progressive stabilization that requires time and involves synaptic plasticity based on the synthesis of new proteins that allow neuronal changes underlying the memory trace storage. Hence, one of the most popular approaches to study the role of any brain structure in memory consolidation has been for many years the administration of protein synthesis inhibitors. Administration of anisomycin in the IC before and after the CS presentation has an effect on LTM (Rosenblum et al., 1993), similarly, the administration of this drug into the central subnucleus of the amygdala (CeA), but not in the BLA affects LTM for CTA (Bahar et al., 2003; De la Cruz et al., 2008; Garcia-DeLaTorre et al., 2009).

As an example of protein expression in the IC and the amygdala related to the CTA consolidation process is the protein c-fos. This protein is an immediate early gene product that regulates the transcription of "late response genes" contributing to long-term neuronal changes (Herdegen and Leah, 1998; Walton et al., 1999). In CTA training, the CS and US association elicits an increase in c-fos expression in the CeA and in the IC (Yamamoto et al., 1997; Wilkins and Bernstein, 2006). Furthermore, the local administration of an antisense oligonucleotide (ASO) in the AMY or in the IC impaired CTA LTM seen in the 24-h test (Yasoshima et al., 2006). Consolidation of CTA is also related to the synthesis of brain-derived neurotrophic factor (BDNF), a neuronal growth factor that has been involved in plasticity-related events such as long-term potentiation (LTP; Messaoudi et al., 2002; Bramham and Messaoudi, 2005) and memory formation of several tasks (Mizuno et al., 2000; Bekinschtein et al., 2008; Ma et al., 2011). Taste aversion learning induces an increase of BDNF expression in the CeA and the IC whereas the inhibition of this expression by local administration of BDNF ASO affects LTM but not STM (Ma et al., 2011). Another protein involved in CTA consolidation is CREB, it has been reported that the administration of ASO of CREB into the AMY before CTA training produced significant deficits on LTM measured 3-5 days after conditioning, however, STM remained intact (Lamprecht et al., 1997). These particular examples provide evidence that some proteins engaged in synaptic plasticity and memory consolidation are mainly related to the consolidation of CTA CS-US association and not only to CS or US exposure, indicating a role in the stabilization of the memory trace formed by the stimuli pairing.

\section{NEUROTRANSMITTERS INVOLVED IN POST-ACQUISITION ACTIVITY FOR TASTE MEMORY CONSOLIDATION}

It has been proposed that long-term stabilization of memory may need reactivation of the biochemical pathways that were initially active during training in order to sustain the levels of proteins required for the ongoing consolidation process. This hypothesis is supported by evidence showing that NMDA receptor synthesis and activity is required for memory consolidation. In this regard, Cui et al. (2005) demonstrated by using a specific inducible knockout mouse that CTA impairments are evident when the NR1 subunit of the NMDAr in the forebrain regions was decreased from 1 up to 3 weeks after CTA training,. These results suggest that a prolonged glutamatergic/NMDAr activity is engaged in CTA LTM formation (Shimizu et al., 2000; Cui et al., 2005). Similarly, memory impairments for taste aversion memory have been demonstrated by the blockade of NMDAr activity at 30,60, or $120 \mathrm{~min}$ after CTA acquisition (Gutierrez et al., 2003). Altogether these results are in accordance with the cellular consolidation theory stating that molecular changes that underlie consolidation might occur within hours or even days after the post-trial stage. Within these molecular changes neurotransmitters release has been scarcely studied. Recently, we have reported by using in vivo microdialysis that the CS-US pairing in CTA training induces a significant concomitant increase of glutamate and dopamine within the IC. As we can see in Figure 3, while monitoring CTA training, saccharin exposure induces a dopamine increase and the LiCl administration induces a glutamate increase in the IC. Interestingly, about $40 \mathrm{~min}$ after the association of both stimuli, dopamine and glutamate extracellular levels showed again a significant and transient increase. Nonetheless, this phenomenon was not related to the CS or US presentation alone, since saccharin followed by $\mathrm{NaCl}$ administration, or water followed by $\mathrm{LiCl}$ did not produce any of the post-acquisition neurotransmitters release as observed after the saccharin-LiCl association. Furthermore, the backward conditioning, which involves the same stimuli that were associated, failed to induce such post-learning changes in dopamine and glutamate. Altogether, these results indicated that only the forward association of the stimuli induced post-trial increments of 
A

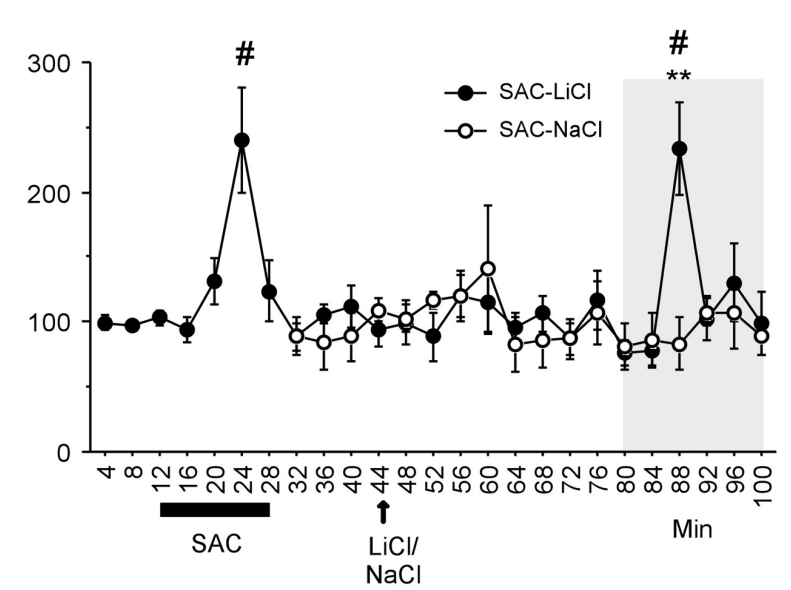

C

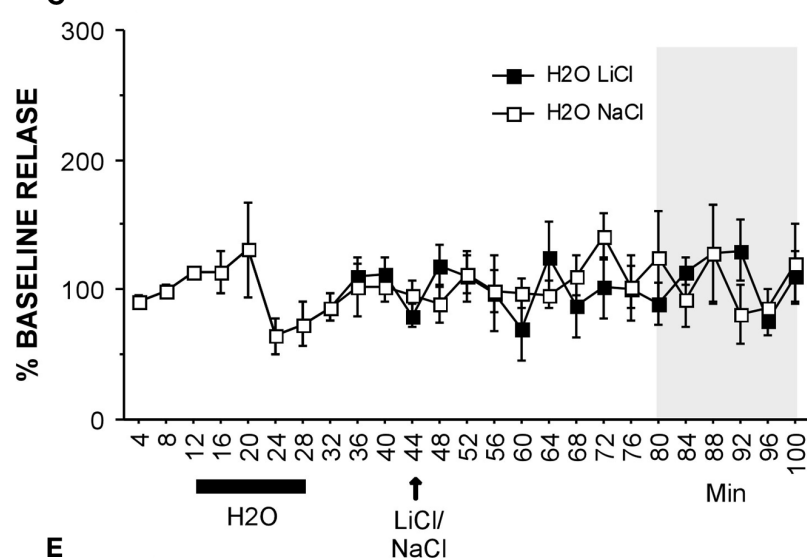

E

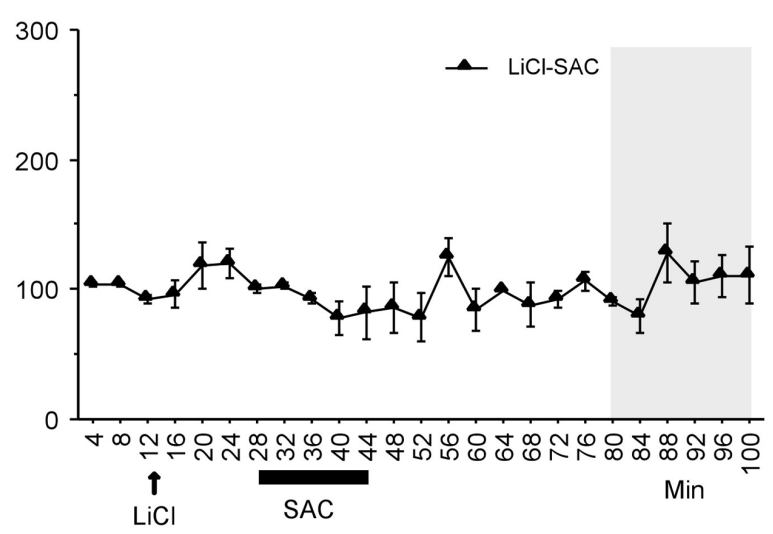

B

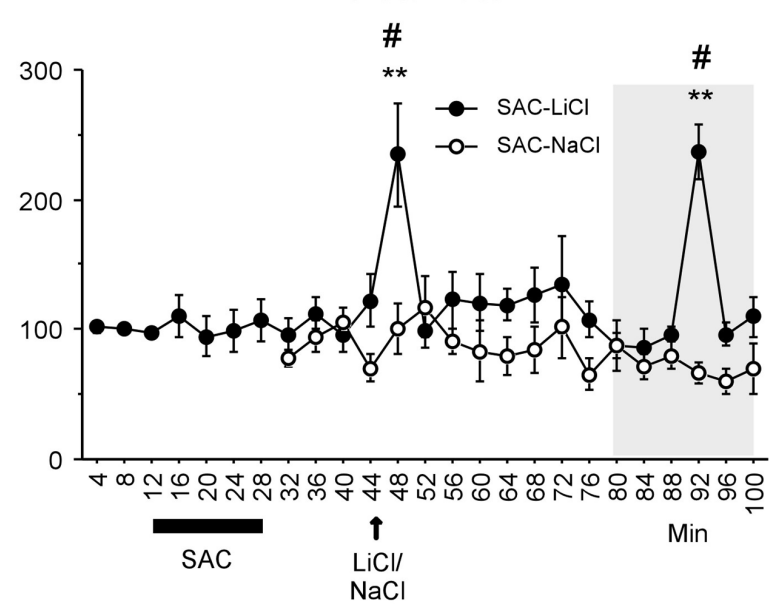

D

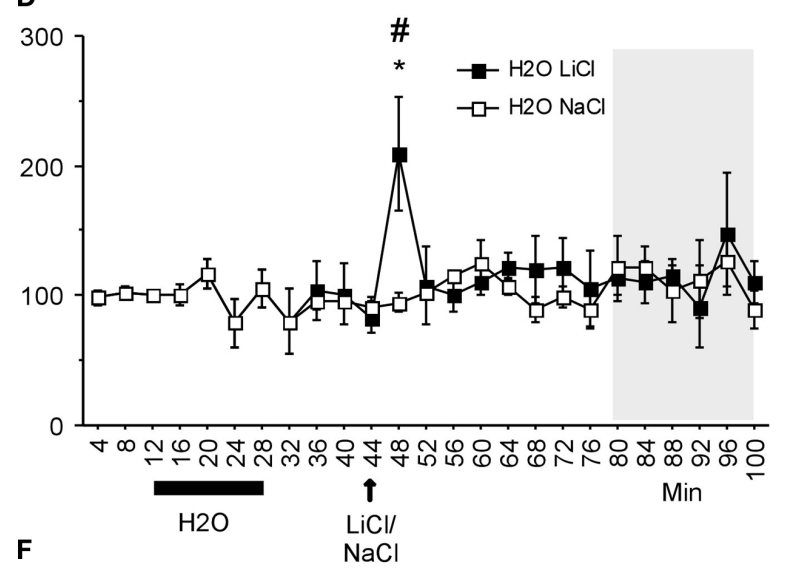

LiCl-SAC

group $(n=5)$ received tap water followed by $0.4 \mathrm{M} \mathrm{LiCl} \mathrm{i.p.;} \mathrm{H}_{2} \mathrm{O}-\mathrm{NaCl}$ group $(n=6)$ received tap water followed by $0.4 \mathrm{M} \mathrm{NaCl}$ i.p.; Dopamine levels are significantly different during saccharin exposure that during water exposure and showed no post-acquisition increments. (D) Glutamate responses to the $\mathrm{LiCl}$ and $\mathrm{NaCl}$ injection showed no post-acquisition changes, only the one related to the US. (E) Dopamine responses during backward conditioning: LiCl-SAC ( $n=7)$, received $0.4 \mathrm{M} \mathrm{LiCl} \mathrm{i.p.,} \mathrm{and} \mathrm{later,} \mathrm{a}$ $0.1 \%(\mathrm{wt} / \mathrm{vol})$ saccharin solution; there is no post-acquisition increment. (F) Glutamate response during the backward conditioning. Graphics expressed as means of $\%$ baseline release \pm SEM. ${ }^{*} p<0.05$, and ${ }^{* *} p<0.01$ vs. control group and $\# p<0.05$ vs. baseline release (Guzman-Ramos et al., 2010). 
glutamate and dopamine. These neurochemical signals appear to be related specifically to the consolidation process, since blockade of the NMDAr in the post-acquisition stage impairs only long, but not STM and the simultaneous blockade of the dopaminergic D1 receptors and the NMDA induces a greater impairment in CTA consolidation, suggesting a synergic role of these neurotransmitter systems (Guzman-Ramos et al., 2010).

A considerable amount of evidence indicates that D1 receptors activity can modify the strength of synaptic transmission, potentiating NMDAr conductance by means of NR1 subunit phosphorylation through PKA, enhancing the excitability of neurons and leading to a cooperative action that may strengthen the memory trace formation (Cepeda et al., 1998; Wang and O'Donnell, 2001; Jay, 2003; Tseng and O'Donnell, 2003, 2004; Hallett et al., 2006). The role of the dopaminergic system in synaptic plasticity and memory consolidation has been proven, particularly through the activation of $\mathrm{cAMP} / \mathrm{PKA} / \mathrm{CREB}$ pathway involving protein synthesis induction (see Jay, 2003). Similarly, dopamine has also been related to the persistence of the LTM trace, since the intrahippocampal infusion of a D1 agonist $9 \mathrm{~h}$ after training in a one-step inhibitory avoidance task makes a weak training last longer, indicating that dopaminergic signal can modulate the maintenance of LTM storage through a post-acquisition activity (Rossato et al., 2009).

Further mechanisms are involved in the long-term maintenance of the CTA memory trace, for instance, the cortical activity of PKM $\zeta$, a Protein Kinase C (PKC) isoform that is persistently active after the consolidation period, is necessary for persistence of memory for several weeks and even after 3 months from the CTA training; the blockade of this enzyme in the IC impairs LTM in an apparently irreversible way (Shema et al., 2007, 2009). Moreover, the over expression of PKM $\zeta$ in this brain structure about 2 weeks after training, enhances LTM performance in the CTA tests (Shema et al., 2011). On the other hand, the post-acquisition blockade of PKM $\zeta$ in the BLA has no effect on LTM maintenance, but PKM $\zeta$ inactivation 15 min after CS presentation, in the CSUS interval, produces a significant effect on taste aversion tested 2 days after conditioning (Gamiz and Gallo, 2011). This implies that CTA memory trace maintenance is dependent on the activity of this enzyme within the IC, and its role on the AMY may be related to the acquisition stage.

\section{AMYGDALA AND INSULAR CORTEX INTERACTION ON CTA LONG-TERM STORAGE}

The amygdala and the IC have reciprocal projections (Pitkanen, 2000; Price, 2003); and some data suggests that the BLA projection to the gustatory cortex is important for the taste aversion memory stabilization. For instance, it has been demonstrated that tetanic stimulation of BLA induces LTP in the IC, increasing the neuronal response to low frequency stimulation (Escobar et al., 1998b; Jones et al., 1999). Thus, LTP induction in the BLA-IC projection before CTA acquisition enhances this task retention by making the extinction process slower (Escobar and BermudezRattoni, 2000). In agreement with the role of NMDAr on memory consolidation, it was demonstrated that such potentiation depends on the NMDAr activity in the IC, since intra-cortical administration of antagonists of this receptors impair both CTA and
LTP induction in the BLA-IC pathway (Escobar et al., 1998a,b). Conversely, the possibility that amygdala NMDA activation could improve taste aversive memory has been demonstrated. Thus, BLA administration of glutamate before the gastric malaise induction during CTA training enhances aversive taste memory formation, and local administration of an NMDAr antagonist in the IC $1 \mathrm{~h}$ after conditioning impaired taste aversion memory enhancement (Ferreira et al., 2005). This suggests that the interaction among amygdala and IC through the glutamatergic system could contribute to the CTA memory trace establishment and consolidation even in post-acquisition stages. In this regard, amygdala postacquisition activity seems to be required for CTA consolidation since the reversible inactivation of this structure by tetrodotoxin (TTX, a voltage-sensitive sodium channel blocker) $15 \mathrm{~min}$ and up to $1.5 \mathrm{~h}$ after CS-US pairing attenuates CTA memory, such attenuation is inversely proportional to the time interval between the acquisition and the intra-amygdalar injection of TTX (Roldan and Bures, 1994).

The amygdala functional integrity is also required for aforementioned post-acquisition neurochemical changes seen in the IC related to previous CS-US association; thus reversible postacquisition blockade of the amygdala with bilateral TTX infusion hindered post-acquisition glutamate and dopamine increments in the IC and impaired CTA consolidation (Guzman-Ramos et al., 2010). Accordingly, these results indicate that amygdala activation is associated to IC post-acquisition activity. In addition, it would be possible that the amygdala needs to be re-activated after the acquisition of the task to outline the memory trace, which is consistent with the evidence that post-training brain activity is related to previous learning experience (Peigneux et al., 2006; Eschenko and Sara, 2008; Lansink et al., 2008; Marrone et al., 2008). Particularly in the amygdala, single unit recordings of spontaneous activity revealed that the firing rate of BLA neurons increased gradually after inhibitory avoidance training (tone paired with footshock), peaking at 30-50 min post-shock (Pelletier et al., 2005), a time frame that goes in accordance with the neurochemical reactivation herein described and with the effect of amygdalar post-acquisition manipulations that enhance memory. There is ample literature showing that emotionally arousing experiences have been related to increase in stress hormones such as glucocorticoids, exerting their central effect in the amygdala through the activation of $\beta$-adrenergic receptors (Ferry et al., 1999; Ferry and McGaugh, 2000; Roozendaal, 2000; McGaugh and Roozendaal, 2002). In this regard, CTA memory retention is enhanced after post-acquisition administration of corticosterone into the BLA and the IC (Miranda et al., 2008). Taken together, these results support the idea that keeping emotional experience in the long-term requires amygdala activity not only during the acquisition period through stimuli signaling, but through post-learning stages.

The post-acquisition engagement of the amygdalar activity has been related to the idea of spontaneous oscillatory activity in this structure that is generated by emotionally arousing conditions. Thus, neuronal recordings in freely moving animals have revealed that during these kind of experiences the firing rate of the BLA neurons increases and it is synchronized trough a theta frequency (4-7 Hz; Pelletier and Pare, 2004). Since theta activity dominates 
during the learning period (Pare and Collins, 2000; Seidenbecher et al., 2003) the main consequence of the amygdalar oscillations is to produce temporal windows of neuronal discharging that facilitates the interaction among the structures that synchronized during the acquisition period (Pare et al., 2002), as could be the case of IC and AMY during CTA. This way, theta frequency activity would enhance the depolarization of afferent structures generating a neurochemical reactivation and promoting synaptic plasticity. For instance, it has been reported that CTA training produces an increment in BLA-IC functional connectivity seen as an increased correlation in the activity of simultaneously recorded neurons of these structures (Grossman et al., 2008). Therefore, plastic changes underlying memory trace consolidation, may need reactivation of particular biochemical pathways to sustain the levels of proteins that are required for the consolidation of memory (Wang et al., 2006).

\section{POST-TRAINING MOLECULAR CHANGES INVOLVED IN MEMORY CONSOLIDATION}

In order to consolidate a memory trace the activation of several intracellular pathways must be triggered modulating protein synthesis and synaptic plasticity. For instance, the activation of the extracellular responsive kinase 1-2 (ERK1-2) in the IC is required for long- but not STM of CTA (Berman et al., 1998). However the implications of this kinase in post-acquisition stages of this task have not been assessed. Interestingly, a fear conditioning task induces two waves of ERK1-2 activation in the lateral amygdala and the BLA, the fist $60 \mathrm{~min}$ after conditioning and the second one about $6 \mathrm{~h}$ post-acquisition (Trifilieff et al., 2006). Similarly, a 60-min increase in ERK1-2 activity after paired presentation of tone and shock has been reported, and this effect is absent with the presentation of the CS or the US alone, or an unpaired tone-shock presentation (Schafe et al., 1999); which implies that the learning experience generates delayed reactivations that could be involved in the consolidation process. In a similar way, PKA activity is required for long-term stabilization of CTA memory, the inhibition of PKA in the IC during the post-acquisition stage impairs long- but not STM (Guzman-Ramos et al., 2010), in accordance with the dopamine and glutamate reactivations that are shown in this structure. Hence, dopaminergic modulation may facilitate the reactivation of PKA in aversive associative tasks, for instance the blockade of D1 receptors in the hippocampus after 3 or $6 \mathrm{~h}$ impair one-step inhibitory avoidance consolidation, and that the inhibition of PKA on the same temporal patterns renders the same effect (Bernabeu et al., 1997). As mentioned, the activation of kinases has a modulatory effect on protein synthesis and particularly expression of IEG like c-fos. In this regard, there is evidence of IEG expression after post-acquisition reactivation related to previous learning; that is, rats trained in the odor discrimination task had more c-fos expression than unpaired control rats in their prelimbic cortex, ventrolateral orbital cortex, and BLA (Tronel and Sara, 2002). Similarly, in a one-trial learning paradigm in which mice learned to enter a dark compartment to escape from an aversively illuminated area showed more Arg 3.1/Arc mRNA expression $15 \mathrm{~min}$ and $4.5 \mathrm{~h}$ post-training detected specifically in the learning group when compared to the control or the retrieval groups (Montag-Sallaz and Montag, 2003).
This kind of monitoring of protein expression after learning should provide patterns about the timeline of the required neuronal changes that underlie memory stabilization in the longterm. In this regard, CTA consolidation and some related protein expression waves has been reported, the IEG HZF- 3 increases in the BLA at 1 and $3 \mathrm{~h}$ after CTA conditioning and this up-regulation is not present with the presentation of the flavor or the malaise induction only, supporting the idea of a specific role in the associative learning (Ge et al., 2003). Recent reports showed an interesting temporal dichotomy in the expression of BDNF in the IC and nuclei of the amygdala. Thus, from 2 to $6 \mathrm{~h}$ after CTA conditioning there was a significant BDNF increase within the CeA, and from 4 to $6 \mathrm{~h}$ an increase was observed in the IC and in the BLA, these up-regulations were related to the association of the stimuli, since the CS or the US alone and a delayed paring of CS-US did not induce BDNF increases (Ma et al., 2011).

\section{CONCLUSION}

As we have seen, many of the post-acquisition molecular changes in the amygdala or in the IC overlap shortly after conditioning, form $45 \mathrm{~min}$ to $1 \mathrm{~h}$, and other waves of activity in at least $6 \mathrm{~h}$, suggesting that there is a time frame where neurochemical changes trigger receptors and kinases activation leading to increased expression of proteins required for memory consolidation. Whether such reactivations are occurring repeatedly is still unclear, but several reports have indicated reactivation activity within a time frame that goes in accordance with cellular consolidation theory (Dudai, 2004). Thus, the neuronal changes caused by up-regulation of protein synthesis within the learning-engaged structures may occur within few hours or even days, as the Cui et al. (2005) have suggested. Such protein synthesis induction appears to be related to spontaneous activity after the exposure to the information (i.e., CS-US association). These kinds of mechanisms involved in the progressive stabilization of the information may be related to the salience of such information, or what we have been calling "emotional memories," which may be of life-saving importance for the animal. Such is the case of CTA learning where a specific flavor may be toxic and could have deadly consequences in the future. The relevance of the information may induce mechanisms that reinforce the memory trace in an efficient way to prompt retrieval and adequate behavioral change. We propose that this could be achieved by post-acquisition reactivation signals during post-training wakefulness. As mentioned, simultaneous neural recordings in the macaque neocortex, revealed that cells in all four areas exhibited firing related to the task (sequential reaching behavior), and those cells tended to be coactive afterward (Hoffman and McNaughton, 2002). Another example is the sequential replay in hippocampal place cells, where population activity in the hippocampus was recorded while rats ran back and forth on a linear track for a water reward at each end. During the run, each neuron's firing was tuned to a particular location along the track, which was stable from lap to lap. These locations define a temporal sequence of place-cell firing on the timescale of seconds. During awake period immediately after the spatial task, the same neurons fired again on the timescale of hundreds of milliseconds, but in the reverse temporal order, which may serve to propagate information from the rewarded location backward along incoming 
trajectories (Foster and Wilson, 2006; Diba and Buzsaki, 2007). It is suggested that such replay might constitute a general mechanism of learning and memory because this is more readily observable in a new environment than a familiar one (Foster and Wilson, 2006). We propose that in CTA memory the post-acquisition activity involves amygdalar spontaneous reactivation that triggers neuronal changes within the IC since it can engage into oscillatory

\section{REFERENCES}

Bahar, A., Samuel, A., Hazvi, S., and Dudai, Y. (2003). The amygdalar circuit that acquires taste aversion memory differs from the circuit that extinguishes it. Eur. J. Neurosci. 17, $1527-1530$.

Bassareo, V., and Di Chiara, G. (1997). Differential influence of associative and nonassociative learning mechanisms on the responsiveness of prefrontal and accumbal dopamine transmission to food stimuli in rats fed ad libitum. J. Neurosci. 17, 851-861.

Bekinschtein, P., Cammarota, M., Katche, C., Slipczuk, L., Rossato, J. I., Goldin, A., Izquierdo, I., and Medina, J. H. (2008). BDNF is essential to promote persistence of long-term memory storage. Proc. Natl. Acad. Sci. U.S.A. 105, 2711-2716.

Berman, D. E., Hazvi, S., Neduva, V., and Dudai, Y. (2000). The role of identified neurotransmitter systems in the response of insular cortex to unfamiliar taste: activation of ERK12 and formation of a memory trace. J. Neurosci. 20, 7017-7023.

Berman, D. E., Hazvi, S., Rosenblum, K., Seger, R., and Dudai, Y. (1998). Specific and differential activation of mitogen-activated protein kinase cascades by unfamiliar taste in the insular cortex of the behaving rat. J. Neurosci. 18, 10037-10044.

Bermudez-Rattoni, F. (2004). Molecular mechanisms of taste-recognition memory. Nat. Rev. Neurosci. 5, 209-217.

Bernabeu, R., Bevilaqua, L., Ardenghi, P., Bromberg, E., Schmitz, P., Bianchin, M., Izquierdo, I., and Medina, J. H. (1997). Involvement of hippocampal cAMP/cAMP-dependent protein kinase signaling pathways in a late memory consolidation phase of aversively motivated learning in rats. Proc. Natl. Acad. Sci. U.S.A. 94, 7041-7046.

Bramham, C. R., and Messaoudi, E. (2005). BDNF function in adult synaptic plasticity: the synaptic consolidation hypothesis. Prog. Neurobiol. 76, 99-125.

Cepeda, C., Colwell, C. S., Itri, J. N., Chandler, S. H., and Levine, M. S. (1998). Dopaminergic modulation of NMDA-induced whole cell currents in neostriatal neurons in slices: contribution of calcium conductances. J. Neurophysiol. 79, 82-94.

Cui, Z., Lindl, K. A., Mei, B., Zhang, S., and Tsien, J. Z. (2005). Requirement of NMDA receptor reactivation for consolidation and storage of nondeclarative taste memory revealed by inducible NR1 knockout. Eur. J. Neurosci. 22, 755-763.

Davis, H. P., and Squire, L. R. (1984). Protein synthesis and memory: a review. Psychol. Bull. 96, 518-559.

De la Cruz, V., Rodriguez-Ortiz, C. J., Balderas, I., and Bermudez-Rattoni, F. (2008). Medial temporal lobe structures participate differentially in consolidation of safe and aversive taste memories. Eur. J. Neurosci. 28, 1377-1381.

De Leonibus, E., Verheij, M. M., Mele, A., and Cools, A. (2006). Distinct kinds of novelty processing differentially increase extracellular dopamine in different brain regions. Eur. J. Neurosci. 23, 1332-1340. Forward and reverse hippocampal place-cell sequences during ripples. Nat. Neurosci. 10, 1241-1242.

Dudai, Y. (2004). The neurobiology of consolidations, or, how stable is the engram? Annu. Rev. Psychol. 55, 51-86.

Ellenbogen, J. M., Payne, J. D., and Stickgold, R. (2006). The role of sleep in declarative memory consolidation: passive, permissive, active or none? Curr. Opin. Neurobiol. 16, 716-722.

Eschenko, O., and Sara, S. J. (2008). Learning-dependent, transient increase of activity in noradrenergic neurons of locus coeruleus during slow wave sleep in the rat: brain stem-cortex interplay for memory consolidation? Cereb. Cortex 18, 2596-2603.

Escobar, M. L., Alcocer, I., and Chao, V. (1998a). The NMDA receptor antagonist CPP impairs conditioned taste aversion and insular cortex longterm potentiation in vivo. Brain Res. 812, 246-251.

Escobar, M. L., Chao, V., and BermudezRattoni, F. (1998b). In vivo longterm potentiation in the insular cortex: NMDA receptor dependence. Brain Res. 779, 314-319.
Diba, K., and Buzsaki, G. (2007). activity related to emotional learning promoting the facilitation of the neuronal interactions strengthening the memory trace.

\section{ACKNOWLEDGMENTS}

Supported by CONACYT 060478 and DEGAPA-UNAM IN216709-3, and the Department of Psychology Texas A\&M University.

Escobar, M. L., and Bermudez-Rattoni, F. (2000). Long-term potentiation in the insular cortex enhances conditioned taste aversion retention. Brain Res. 852, 208-212.

Feenstra, M. G., Botterblom, M. H., and Mastenbroek, S. (2000). Dopamine and noradrenaline efflux in the prefrontal cortex in the light and dark period: effects of novelty and handling and comparison to the nucleus accumbens. Neuroscience 100, 741-748.

Fernandez-Ruiz, J., Miranda, M. I., Bermudez-Rattoni, F., and DruckerColin, R. (1993). Effects of catecholaminergic depletion of the amygdala and insular cortex on the potentiation of odor by taste aversions. Behav. Neural Biol. 60, 189-191.

Ferreira, G., Gutierrez, R., De La Cruz, V., and Bermudez-Rattoni, F. (2002). Differential involvement of cortical muscarinic and NMDA receptors in short- and long-term taste aversion memory. Eur. J. Neurosci. 16, 1139-1145.

Ferreira, G., Miranda, M. I., De la Cruz, V., Rodriguez-Ortiz, C. J., and Bermudez-Rattoni, F. (2005). Basolateral amygdala glutamatergic activation enhances taste aversion through NMDA receptor activation in the insular cortex. Eur. J. Neurosci. 22, 2596-2604.

Ferry, B., and McGaugh, J. L. (2000). Role of amygdala norepinephrine in mediating stress hormone regulation of memory storage. Acta Pharmacol. Sin. 21, 481-493.

Ferry, B., Roozendaal, B., and McGaugh, J. L. (1999). Role of norepinephrine in mediating stress hormone regulation of long-term memory storage: a critical involvement of the amygdala. Biol. Psychiatry 46, 1140-1152.

Foster, D. J., and Wilson, M. A. (2006). Reverse replay of behavioural sequences in hippocampal place cells during the awake state. Nature 440, 680-683.

Gais, S., Albouy, G., Boly, M., DangVu, T. T., Darsaud, A., Desseilles, M., Rauchs, G., Schabus, M., Sterpenich, V., Vandewalle, G., Maquet, P., and Peigneux, P. (2007). Sleep transforms the cerebral trace of declarative memories. Proc. Natl. Acad. Sci. U.S.A. 104, 18778-18783.

Gamiz, F., and Gallo, M. (2011). Intraamygdala ZIP injections impair the memory of learned active avoidance responses and attenuate conditioned taste-aversion acquisition in rats. Learn. Mem. 18, 529-533.

Garcia-DeLaTorre, P., Rodriguez-Ortiz, C. J., Arreguin-Martinez, J. L., Cruz-Castaneda, P., and BermudezRattoni, F. (2009). Simultaneous but not independent anisomycin infusions in insular cortex and amygdala hinder stabilization of taste memory when updated. Learn. Mem. 16, 514-519.

Ge, H., Chiesa, R., and Pena de Ortiz, S. (2003). Hzf-3 expression in the amygdala after establishment of conditioned taste aversion. Neuroscience $120,1-4$.

Grossman, S. E., Fontanini, A., Wieskopf, J. S., and Katz, D. B. (2008). Learning-related plasticity of temporal coding in simultaneously recorded amygdalacortical ensembles. J. Neurosci. 28, 2864-2873.

Gutierrez, R., Tellez, L. A., and Bermudez-Rattoni, F. (2003). Blockade of cortical muscarinic but not NMDA receptors prevents a novel taste from becoming familiar. Eur. J.

Guzman-Ramos, K., Osorio-Gomez, D., Moreno-Castilla, P., and BermudezRattoni, F. (2010). Off-line concomitant release of dopamine and glutamate involvement in taste memory consolidation. J. Neurochem. 114, 226-236.

Hallett, P. J., Spoelgen, R., Hyman, B. T., Standaert, D. G., and Dunah, A. W. (2006). Dopamine D1 activation potentiates striatal NMDA receptors by tyrosine phosphorylationdependent subunit trafficking. $J$. Neurosci. 26, 4690-4700.

Herdegen, T., and Leah, J. D. (1998). Inducible and constitutive transcription factors in the mammalian nervous system: control of gene expression by Jun, Fos and Krox, and CREB/ATF proteins. Brain Res. Brain Res. Rev. 28, 370-490. Neurosci. 17, 1556-1562. 
Hoffman, K. L., and McNaughton, B. L. (2002). Coordinated reactivation of distributed memory traces in primate neocortex. Science 297, 2070-2073.

Jay, T. M. (2003). Dopamine: a potential substrate for synaptic plasticity and memory mechanisms. Prog. Neurobiol. 69, 375-390.

Jones, M. W., French, P. J., Bliss, T. V., and Rosenblum, K. (1999). Molecular mechanisms of long-term potentiation in the insular cortex in vivo. J. Neurosci. 19, RC36.

Lamprecht, R., Hazvi, S., and Dudai, Y. (1997). cAMP response elementbinding protein in the amygdala is required for long- but not shortterm conditioned taste aversion memory. J. Neurosci. 17, 8443-8450.

Lansink, C. S., Goltstein, P. M., Lankelma, J. V., Joosten, R. N., McNaughton, B. L., and Pennartz, C. M. (2008). Preferential reactivation of motivationally relevant information in the ventral striatum. J. Neurosci. $28,6372-6382$.

Ljungberg, T., Apicella, P., and Schultz, W. (1992). Responses of monkey dopamine neurons during learning of behavioral reactions. J. Neurophysiol. 67, 145-163.

Ma, L., Wang, D. D., Zhang, T. Y., Yu, H., Wang, Y., Huang, S. H., Lee, F. S., and Chen, Z. Y. (2011). Region-specific involvement of BDNF secretion and synthesis in conditioned taste aversion memory formation. J. Neurosci. 31, 2079-2090.

Marrone, D. F., Schaner, M. J., McNaughton, B. L., Worley, P. F., and Barnes, C. A. (2008). Immediateearly gene expression at rest recapitulates recent experience. J. Neurosci. 28, 1030-1033.

Martin, K. C., Barad, M., and Kandel, E. R. (2000). Local protein synthesis and its role in synapse-specific plasticity. Curr. Opin. Neurobiol. 10, 587-592.

McGaugh, J. L., and Roozendaal, B. (2002). Role of adrenal stress hormones in forming lasting memories in the brain. Curr. Opin. Neurobiol. $12,205-210$

Messaoudi, E., Ying, S. W., Kanhema, T., Croll, S. D., and Bramham, C. R. (2002). Brain-derived neurotrophic factor triggers transcriptiondependent, late phase long-term potentiation in vivo. J. Neurosci. 22, 7453-7461.

Miranda, M. I., Quirarte, G. L., Rodriguez-Garcia, G., McGaugh, J. L., and Roozendaal, B. (2008). Glucocorticoids enhance taste aversion memory via actions in the insular cortex and basolateral amygdala. Learn. Mem. 15, 468-476.
Mizuno, M., Yamada, K., Olariu, A., Nawa, H., and Nabeshima, T. (2000). Involvement of brain-derived neurotrophic factor in spatial memory formation and maintenance in a radial arm maze test in rats. $J$. Neurosci. 20, 7116-7121.

Montag-Sallaz, M., and Montag, D. (2003). Learning-induced arg 3.1/arc mRNA expression in the mouse brain. Learn. Mem. 10, 99-107.

Naor, C., and Dudai, Y. (1996). Transient impairment of cholinergic function in the rat insular cortex disrupts the encoding of taste in conditioned taste aversion. Behav. Brain Res. 79, 61-67.

Pare, D., and Collins, D. R. (2000). Neuronal correlates of fear in the lateral amygdala: multiple extracellular recordings in conscious cats. $J$. Neurosci. 20, 2701-2710.

Pare, D., Collins, D. R., and Pelletier, J. G. (2002). Amygdala oscillations and the consolidation of emotional memories. Trends Cogn. Sci. (Regul. Ed.) 6, 306-314.

Peigneux, P., Orban, P., Balteau, E., Degueldre, C., Luxen, A., Laureys, S., and Maquet, P. (2006). Offline persistence of memory-related cerebral activity during active wakefulness. PLoS Biol. 4, e100. doi: 10.1371/journal.pbio.0040100

Pelletier, J. G., Likhtik, E., Filali, M., and Pare, D. (2005). Lasting increases in basolateral amygdala activity after emotional arousal: implications for facilitated consolidation of emotional memories. Learn. Mem. 12, 96-102.

Pelletier, J. G., and Pare, D. (2004). Role of amygdala oscillations in the consolidation of emotional memories. Biol. Psychiatry 55, 559-562.

Pitkanen, A. (ed.). (2000). Connectivityof the Rat Amygdaloid Complex. New York: Oxford University Press.

Price, J. L. (2003). Comparative aspects of amygdala connectivity. Ann. N. Y. Acad. Sci. 985, 50-58.

Rasch, B., and Born, J. (2007) Maintaining memories by reactivation. Curr. Opin. Neurobiol. 17, 698-703.

Robertson, E. M., Pascual-Leone, A., and Press, D. Z. (2004). Awareness modifies the skill-learning benefits of sleep. Curr. Biol. 14, 208-212.

Roldan, G., and Bures, J. (1994). Tetrodotoxin blockade of amygdala overlapping with poisoning impairs acquisition of conditioned taste aversion in rats. Behav. Brain Res. 65, 213-219.

Roozendaal, B. (2000). 1999 Curt P. Richter award.
Glucocorticoids and the regulation of memory consolidation. Psychoneuroendocrinology $\quad 25$ 213-238.

Rosenblum, K., Meiri, N., and Dudai, Y. (1993). Taste memory: the role of protein synthesis in gustatory cortex. Behav. Neural Biol. 59, 49-56.

Rossato, J. I., Bevilaqua, L. R., Izquierdo, I., Medina, J. H., and Cammarota, M (2009). Dopamine controls persistence of long-term memory storage. Science 325, 1017-1020.

Rossetti, Z. L., and Carboni, S. (2005). Noradrenaline and dopamine elevations in the rat prefrontal cortex in spatial working memory. J. Neurosci. 25, 2322-2329.

Schafe, G. E., Nadel, N. V., Sullivan, G. M., Harris, A., and LeDoux, J. E. (1999). Memory consolidation for contextual and auditory fear conditioning is dependent on protein synthesis, PKA, and MAP kinase. Learn. Mem. 6, 97-110.

Seidenbecher, T., Laxmi, T. R., Stork, O., and Pape, H. C. (2003). Amygdalar and hippocampal theta rhythm synchronization during fear memory retrieval. Science 301, 846-850.

Shema, R., Haramati, S., Ron, S., Hazvi, S., Chen, A., Sacktor, T. C., and Dudai, Y. (2011). Enhancement of consolidated long-term memory by overexpression of protein kinase Mzeta in the neocortex. Science 331 1207-1210.

Shema, R., Hazvi, S., Sacktor, T. C., and Dudai, Y. (2009). Boundary conditions for the maintenance of memory by PKMzeta in neocortex. Learn. Mem. 16, 122-128.

Shema, R., Sacktor, T. C., and Dudai, Y (2007). Rapid erasure of long-term memory associations in the cortex by an inhibitor of PKM zeta. Science 317, 951-953.

Shimizu, E., Tang, Y. P., Rampon, C. and Tsien, J. Z. (2000). NMDA receptor-dependent synaptic reinforcement as a crucial process for memory consolidation. Science 290 , 1170-1174.

Smith, C. (2001). Sleep states and memory processes in humans: procedural versus declarative memory systems. Sleep Med. Rev. 5, 491-506.

Stickgold, R. (2005). Sleep-dependent memory consolidation. Nature 437, 1272-1278.

Trifilieff, P., Herry, C., Vanhoutte, P., Caboche, J., Desmedt, A., Riedel, G., Mons, N., and Micheau, J. (2006). Foreground contextual fear memory consolidation requires two independent phases of hippocampal ERK/CREB activation. Learn. Mem. 13, 349-358.
Tronel, S., and Sara, S. J. (2002). Mapping of olfactory memory circuits: region-specific c-fos activation after odor-reward associative learning or after its retrieval. Learn. Mem. 9, 105-111.

Tseng, K. Y., and O'Donnell, P. (2003). Dopamine-glutamate interactions in the control of cell excitability in medial prefrontal cortical pyramidal neurons from adult rats. Ann. N. Y. Acad. Sci. 1003, 476-478.

Tseng, K. Y., and O'Donnell, P. (2004). Dopamine-glutamate interactions controlling prefrontal cortical pyramidal cell excitability involve multiple signaling mechanisms. $J$. Neurosci. 24, 5131-5139.

Ungless, M. A. (2004). Dopamine: the salient issue. Trends Neurosci. 27 702-706.

Walker, M. P., and Stickgold, R. (2004). Sleep-dependent learning and memory consolidation. Neuron 44, 121-133.

Walton, M., Henderson, C., MasonParker, S., Lawlor, P., Abraham, W. C., Bilkey, D., and Dragunow, M. (1999). Immediate early gene transcription and synaptic modulation. J. Neurosci. Res. 58, 96-106.

Wang, H., Hu, Y., and Tsien, J. Z. (2006). Molecular and systems mechanisms of memory consolidation and storage. Prog. Neurobiol. 79, 123-135.

Wang, J., and O'Donnell, P. (2001). $\mathrm{D}(1)$ dopamine receptors potentiate nmda-mediated excitability increase in layer $\mathrm{V}$ prefrontal cortical pyramidal neurons. Cereb. Cortex 11 , 452-462.

Welzl, H., D'Adamo, P., and Lipp, H. P. (2001). Conditioned taste aversion as a learning and memory paradigm. Behav. Brain Res. 125, 205-213.

Wilkins, E. E., and Bernstein, I. L. (2006). Conditioning method determines patterns of $\mathrm{c}$-fos expression following novel taste-illness pairing. Behav. Brain Res. 169, 93-97.

Yamamoto, T., and Fujimoto, Y. (1991). Brain mechanisms of taste aversion learning in the rat. Brain Res. Bull. 27, 403-406.

Yamamoto, T., Nagai, T., Shimura, T., and Yasoshima, Y. (1998). Roles of chemical mediators in the taste system. Jpn. J. Pharmacol. 76, 325-348.

Yamamoto, T., Sako, N., Sakai, N., and Iwafune, A. (1997). Gustatory and visceral inputs to the amygdala of the rat: conditioned taste aversion and induction of c-fos-like immunoreactivity. Neurosci. Lett. 226, 127-130.

Yasoshima, Y., Sako, N., Senba, E., and Yamamoto, T. (2006). Acute 
suppression, but not chronic genetic deficiency, of c-fos gene expression impairs long-term memory in aversive taste learning. Proc. Natl. Acad. Sci. U.S.A. 103, 7106-7111.

Yasoshima, Y., and Yamamoto, T. (1998). Short-term and long-term excitability changes of the insular cortical neurons after the acquisition of taste aversion learning in behaving rats. Neuroscience 84, 1-5.

Conflict of Interest Statement: The authors declare that the research was conducted in the absence of any commercial or financial relationships that could be construed as a potential conflict of interest.
Received: 27 July 2011; accepted: 31 August 2011; published online: 26 September 2011.

Citation: Guzmán-Ramos $K$ and Bermúdez-Rattoni F (2011) Postlearning molecular reactivation underlies taste memory consolidation. Front. Syst. Neurosci. 5:79. doi: 10.3389/fnsys.2011.00079
Copyright (C) 2011 Guzmán-Ramos and Bermúdez-Rattoni. This is an openaccess article subject to a non-exclusive license between the authors and Frontiers Media SA, which permits use, distribution and reproduction in other forums, provided the original authors and source are credited and other Frontiers conditions are complied with. 